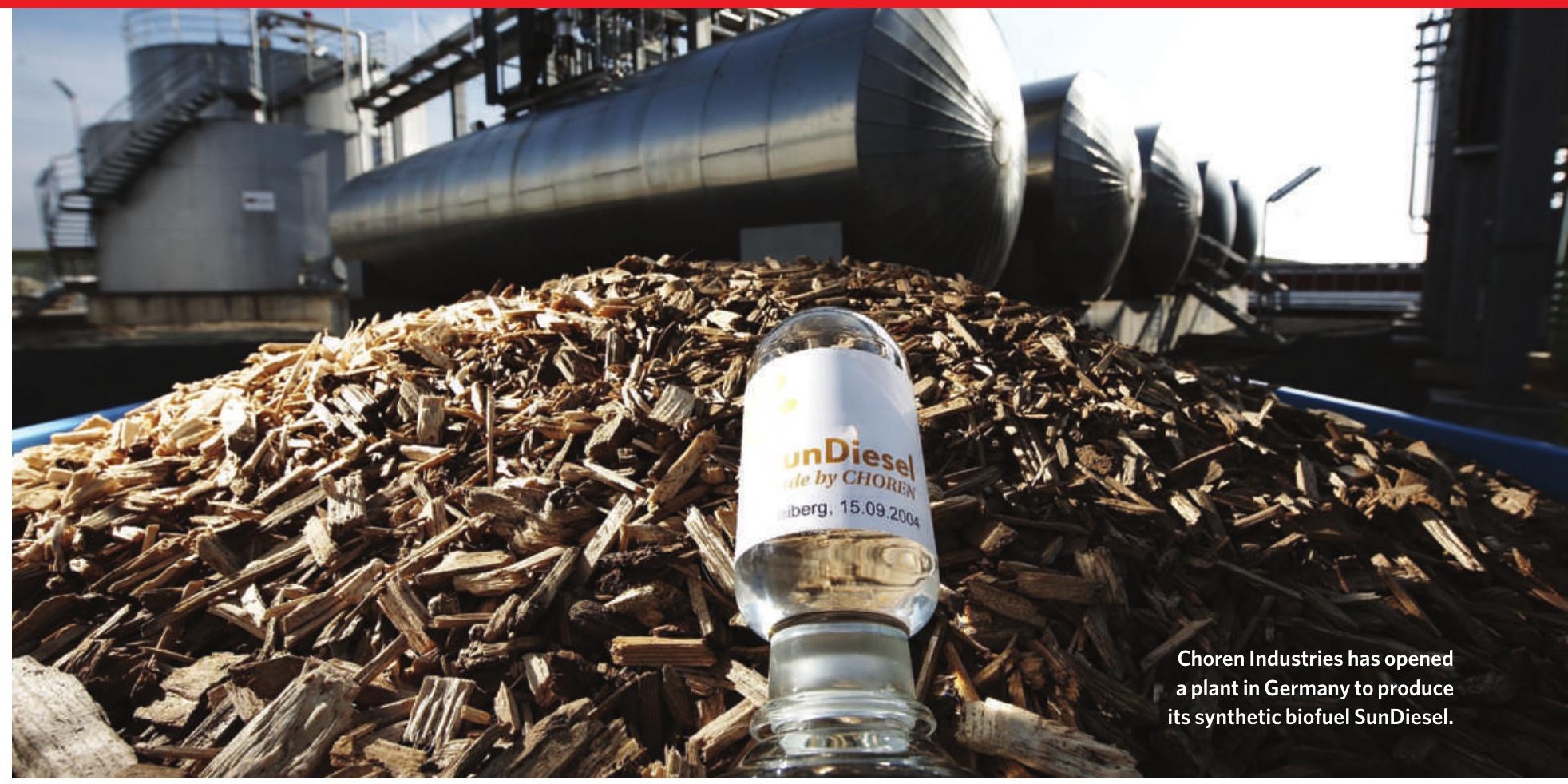

\title{
From plant to power
}

\section{The last of four weekly articles looks at making liquid fuels direct from biomass.}

\section{THE BUSINESS OF BIOFUELS}

Petrol might yet survive the green revolution. Some investors are taking seriously the concept of 'green gasoline' - transforming the woody remains of plants into exact replicas of today's transportation fuels.

Many see promise because, unlike other biofuels, this product would blend smoothly into today's petrol-driven infrastructure. "This is one I like. It's got a chance of making it," says Lanny Schmidt, a chemical engineer who works on combustion processes and alternative fuels at the University of Minnesota in Minneapolis.

Yet this 'biomass-to-liquid' approach is one of the least known in the biofuels portfolio, and barely makes a dent in alternative fuel quotas. A report by the US Foreign Agricultural Service estimates that in 2009 biomass-to-liquid fuels will make up just 2,000 tonnes of oil equivalent for road transportation in the European Union. The figure for bioethanol is 2 million tonnes, and for conventional fossil fuels it is more than 310 million tonnes. The report concludes that the technology for biomass-to-liquid fuels is "in its infancy and will take some years before it reaches a significant volume”.

At least one major oil company has dabbled in the field. In 2008, Royal Dutch Shell invested an undisclosed amount in Virent Energy Systems, a company based in Madison, Wisconsin. The collaboration aims to improve Virent's processes to take sugars generated from cellulosic waste and catalytically react them with water to produce fuel molecules. "It's a premium highoctane [petrol] we're generating," says Randy Cortright, the company's founder and chief technical officer, who co-invented the technology with chemical engineer James Dumesic of the University of Wisconsin-Madison.

But Virent currently produces about a litre a day, and getting that to more significant amounts will take time. "By the end of this year we will have a larger-scale pilot plant capable of 40,000 litres a year," says Cortright. A full-scale plant is some three to six years away.

The technologies required are known but need refinement: they rely on breaking down biomass, such as sugar molecules, which can then be handled in conventional refineries to produce petrol, diesel or jet fuel. But the catalysts needed to convert the biomass to useful hydrocarbons are still being developed, as are ways to break down the biomass so it can be processed.

George Huber, a chemi-
"The promise of these fuels is that oil companies will be able to use them very easily." demonstration plant will take another three or four years and hundreds of millions of dollars, he estimates.

Nevertheless, some money is flowing into the field. Virent has raised \$30 million in venture financing and has commitments of $\$ 40$ million from industry and government funding. Amyris Biotechnologies, a firm in Emeryville, California, that engineers microbes to increase biofuel yield, has amassed $\$ 140$ million since 2006 from high-powered investors including Khosla Ventures and Kleiner Perkins Caufield and Byers.

And late last month LS9, based in South San Francisco, attracted \$25 million from oil and gas company Chevron. LS9 uses specially designed microbes to chew up biomass to produce hydrocarbons that can be refined as usual.

"The promise of these fuels cal engineer from the University of Massachusetts in Amherst, heats biomass so that it decomposes and releases volatile sugars, which are then passed over a zeolite catalyst to form the aromatic molecules benzene, xylene and toluene. These molecules are also extracted from crude oil, and xylene and toluene can be blended with other substances to make petrol. A mixture of these molecules can be produced for less than US\$0.46 per litre, says Huber, who has started a company called Anellotech, to develop the technology further.

Still, investors need patience, he says: "You make your money on volume." To go from labbased processes, such as his, to the pilot stage takes three or four years; to scale up to a large is that oil companies will be able to use them very easily," says Harry Boyle, an analyst at London-based New Energy Finance. "The exit, if you're a venture-capital player, is huge and very exciting."

But it's a long way to a profitable exit. For instance, biofuels producer Dynamotive Energy Systems, based in British Columbia, Canada, posted net losses of Can $\$ 1.5$ million (US $\$ 1.4$ million) in the second quarter of 2009.

Some are looking to federal loans to help out. Terrabon, based in Houston, Texas, announced in July that it had made organic salts from biomass, then turned them into petrol with Valero Energy Corporation, a refining company headquartered in San Antonio, Texas. 
Terrabon, which uses technology developed at Texas A\&M University in College Station, plans to build a bigger plant in Port Arthur, Texas, that can process 55 tonnes of biomass a day, producing 4.9 million litres of fuel a year. It has applied for a $\$ 25$-million grant from the US Department of Energy to build this plant, but if it doesn't get the grant it will invest even more itself and make the plant even larger - to process up to 220 tonnes of biomass each day. If paying for the whole plant, says chief financial officer Malcolm McNeill, "you might as well go to the real size".

Meanwhile, the processing company UOP, based in Des Plaines, Illinois, has developed a pyrolysis technique that heats biomass to release oil. More work is needed to develop that oil into a fuel, but the technology is already being licensed by UOP's joint venture with Canadian company Ensyn Technologies in Ottawa, Ontario. "What this technology has lacked is the economic drivers to make it happen," says Graham Ellis, UOP's business manager for renewable energy and chemicals. UOP wants to help existing refineries to license its upgrading technology to use in existing infrastructure.

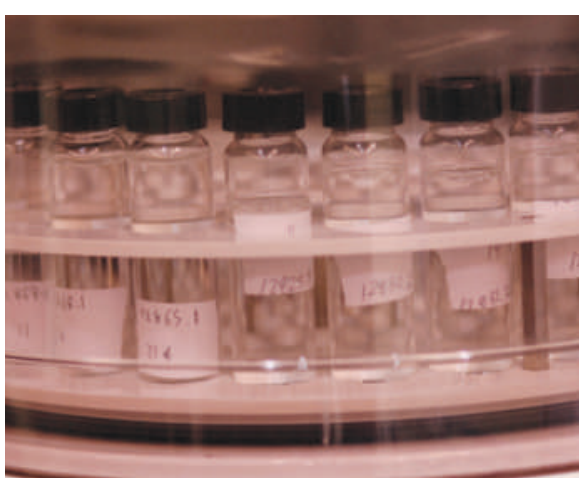

At Virent, researchers are engineering microbes to increase biofuel yield.

In Germany, the car-maker Volkswagen, based in Wolfsburg, is leading a €13.6-million (US\$20-million) project intended to eventually produce 200,000 tonnes per year of liquid fuels from biomass. The processing will be done by Choren Industries in Freiberg. Choren has separately amassed investments of $€ 140$ million, mainly from individual investors, although minority shareholders include Shell Deutschland Oil, Daimler and Volkswagen. It is now commissioning a new plant in Freiberg $\underset{\underline{\underline{u}}}{\stackrel{5}{\mathbf{s}}}$ that will have a nominal capacity of 18 million $\stackrel{\text { }}{>}$ litres of synthetic biofuel per year, all of which will be sold to Shell.

Some producers think they can eventually become competitive by offering a lower-cost product than many other first-generation biofuels. Raw-material costs for synthetic biofuels, says Choren spokeswoman Ines Bilas, can be around $40 \%$ of total costs, compared with nearly $90 \%$ for biodiesel made from rapeseed oil.

The fuel's adaptability may also help it to catch up with other, more established biofuel alternatives. "You really can make [petrol] from sorghum or municipal waste," says McNeill.

But for now, its future rests with process engineers and how well they can streamline the path from woody waste to liquid fuel.

\section{Katharine Sanderson}

\section{Correction}

The News story 'Climate burden of refrigerants rockets' (see Nature 459, 1040-1041; 2009) cited an incorrect year for when hydrofluorocarbon emissions were predicted to reach between 5.5 billion and 8.8 billion tonnes of carbon dioxide equivalent annually. The year is 2050 , not 2010. 